\title{
Spatial patterns of grassland-shrubland state transitions: a 74-year record on grazed and protected areas
}

\author{
Dawn M. Browning, ${ }^{1,2,4}$ Janet Franklin, ${ }^{3}$ Steven R. Archer, ${ }^{2}$ Jeffrey K. Gillan, ${ }^{1}$ and D. Phillip Guertin ${ }^{2}$ \\ ${ }^{1}$ USDA-ARS, Jornada Experimental Range, P.O. Box 30003, MSC 3JER, New Mexico State University, Las Cruces, \\ New Mexico 88003 USA \\ ${ }^{2}$ School of Natural Resources and Environment, University of Arizona, Tucson, Arizona 85721 USA \\ ${ }^{3}$ School of Geographical Sciences and Urban Planning, Arizona State University, Tempe, Arizona 85287 USA
}

\begin{abstract}
Tree and shrub abundance has increased in many grasslands causing changes in ecosystem carbon and nitrogen pools that are related to patterns of woody plant distribution. However, with regard to spatial patterns of shrub proliferation, little is known about how they are influenced by grazing or the extent to which they are influenced by intraspecific interactions. We addressed these questions by quantifying changes in the spatial distribution of Prosopis velutina (mesquite) shrubs over 74 years on grazed and protected grasslands. Livestock are effective agents of mesquite dispersal and mesquite plants have lateral roots extending well beyond the canopy. We therefore hypothesized that mesquite distributions would be random on grazed areas mainly due to cattle dispersion and clustered on protected areas due to decreased dispersal and interspecific interference with grasses; and that clustered or random distributions at early stages of encroachment would give way to regular distributions as stands matured and density-dependent interactions intensified. Assessments in 1932, 1948, and 2006 supported the first hypothesis, but we found no support for the second. In fact, clustering intensified with time on the protected area and the pattern remained random on the grazed site. Although shrub density increased on both areas between 1932 and 2006, we saw no progression toward a regular distribution indicative of density-dependent interactions. We propose that processes related to seed dispersal, grass-shrub seedling interactions, and hydrological constraints on shrub size interact to determine vegetation structure in grasslandto-shrubland state changes with implications for ecosystem function and management.
\end{abstract}

Key words; LISA; livestock exclusion; mesquite; Moran's I; pair correlation function; point pattern analysis; Prosopis velutina; Ripley's K; Sonoran Desert; spatial autocorrelation; spatial ecology.

\section{INTRODUCTION}

The spatial arrangement and size of plants mediates ecosystem function in water-limited ecosystems by influencing soil erosion and deposition, decomposition, spread of disturbance, and land use (Ludwig et al. 2005, de Knegt et al. 2008, Neff et al. 2008). In ecosystems undergoing state transitions, the reordering of plant functional groups contributes to major shifts in ecosystem function by eliciting changes in biophysical processes (Ellison et al. 2005) and responses to external drivers (Scheffer and Carpenter 2003). In grasslands and savannas undergoing state-transitions caused by woody plant proliferation (Van Auken 2000, Naito and Cairns 2011), structural changes are dramatic, with significant consequences for ecosystem function (Barger et al. 2011, Eldridge et al. 2011) and management (Bestelmeyer et al. 2011). Although increases in the abundance of shrubs and trees have been widely reported, less emphasis has been placed on how spatial patterns develop on

Manuscript received 30 October 2013; accepted 10 December 2013; final version received 13 January 2014. Corresponding Editor: J. A. Ludwig.

${ }^{4}$ E-mail: dbrownin@nmsu.edu landscapes as new individuals are recruited and existing plants grow. When woody plants proliferate in grasslands, changes in soil organic carbon and nitrogen pools are closely tied to patterns of shrub distribution. A better understanding of spatial patterns accompanying woody cover change could therefore improve our ability to predict landscape-scale changes in ecosystem carbon and nitrogen cycling accompanying changes in vegetation structure, shed light on the relative importance of the interacting factors driving or constraining shifts in life-form abundance, and increase our understanding of feedbacks involved with state transitions and their thresholds (Peters et al. 2004).

Livestock grazing is the most geographically extensive form of land use worldwide (Asner et al. 2004) and heavy grazing by domestic herbivores in the late 1800 s and early- to mid-1900s is a shared history for many of the world's arid and semiarid ecosystems (hereafter drylands; Ash et al. 1997, Holechek et al. 2000). Spatial patterning of vegetation resulting from livestock grazing can be substantial (Rietkerk et al. 2000), reflecting both direct and indirect influences on seed dispersal, seedling recruitment, gap formation, plant competition, soil properties, and fire (Archer 1994, Fuhlendorf et al. 
2008). Woody plant proliferation in drylands often occurs against this backdrop of altered patterns in the soil surface and herbaceous cover. As the size and density of shrubs increases atop this matrix, so too does the spatial heterogeneity of soil properties (e.g., Throop and Archer 2008) and the nature of erosion-fire feedbacks (Okin et al. 2009, Ravi and D'Odorico 2009), typically culminating in the transition from grass- to shrub-dominated states that represent major shifts in ecosystem function (Archer 2010, Eldridge et al. 2011).

Studies on the effects of livestock grazing on vegetation spatial patterns have largely focused on herbaceous plants (Adler et al. 2001, Rayburn and Monaco 2011). Grazing-induced changes in patterns of species composition, above- and belowground biomass and the size of non-vegetated gaps can influence woody plant seedling emergence and survival (e.g., Jurena and Archer 2003, Montané et al. 2012) and hence patterns of shrub distribution (Seifan and Kadmon 2006). Furthermore, grazing may intensify shrub-inter-shrub contrasts (Allington and Valone 2010). Studies that quantify spatial patterns, spatially structured population dynamics, and their change (e.g., Condit et al. 2000, Miriti 2007, Rayburn and Monaco 2011) therefore have the potential to enhance our understanding of livestock grazing influences on species interactions and environmental heterogeneity in ways not possible with shortterm, fine-scale experiments.

Woody plant encroachment since the late 1800s/early 1900s has been well documented in desert grasslands of southeastern Arizona (McClaran 2003). Analysis of temporal changes in shrub cover revealed two distinct phases on sandy loam uplands: an active encroachment phase from 1900 through the 1930s, followed by a stabilization phase from the 1960s through the present (Browning et al. 2008). The encroachment phase was characterized by pronounced net increases in woody plant cover and transition from a perennial grassdominated state to a mixed savanna state, whereas the stabilization phase was characterized by oscillations around a mean of approximately $35 \%$ shrub canopy cover to a shrubland state. A companion study, based on census data from grazing exclosure plots established in 1932 and re-mapped in 1948 and 2006, further revealed that removal of livestock in this historically grazed system resulted in enhanced shrub recruitment relative to grazed areas over the 74-year period (Browning and Archer 2011). With the current study we sought to utilize spatially explicit records from the plots established in 1932 to quantify how spatial patterns of shrub distribution changed with these changes in shrub cover and abundance and to determine the extent to which the presence or removal of livestock may have influenced those patterns. Although quantifying spatial patterns may not permit clear identification of the process or processes that generate them, it is akin to the multiple working hypothesis approach (Cham- berlin 1965) in that it can provide evidence that is consistent with certain processes and rule out others (Perry et al. 2006, Franklin 2010).

\section{OBjectives/Hypotheses}

Our objectives were to use census data from 1932, 1948 and 2006 for the invasive shrub Prosopis velutina (velvet mesquite) to compare an area historically grazed by livestock since the mid-to-late 1800 s to that of a heavily grazed area subsequently protected from livestock since 1932. Our comparisons focused on: spatial patterns of shrubs; spatial autocorrelation of shrub density at plant neighborhood and plot scales; and distances between shrubs (hereafter inter-shrub distances).

In addressing these objectives we tested hypotheses regarding the effects of livestock removal on patterns of shrub proliferation across space and time. In the spatial dimension, we hypothesized that removal of livestock would result in a greater degree of clustering in mesquite individuals relative to areas where livestock grazing has persisted. Although mesquite is dispersed by both rodents (Glendening 1952) and livestock (Kneuper et al. 2003), livestock are better vectors of long-distance seed dispersal and are potentially more effective in terms of the number of seeds dispersed and enhancing the probability of successful germination and establishment (Brown and Archer 1987). Removal of the livestock seed dispersal vector should therefore reduce recruitment away from parent plants and thereby indirectly promote a clustered distribution at short distances approximating canopy radii. Conversely, livestock promote heterogeneity in vegetation via grazing and trampling of emergent plants (Huntly 1991, Rayburn and Monaco 2011), so patterns on the protected area are expected to be clustered relative to the adjacent grazed site.

Shrub cover in recent decades at this site has fluctuated around 35\% (Browning et al. 2008), a level that approximates the predicted carrying capacity for woody vegetation for the mean annual rainfall at this site (Sankaran et al. 2005). We therefore hypothesized that in the temporal dimension, shrub distributions in 1948 would become regular (uniformly distributed) by 2006 as mesquite stands developed and matured. This outcome would be expected if dispersal of mesquite seeds by rodents and livestock and their subsequent establishment was clumped or random during the encroachment phase, with density-dependent interactions (self-thinning) generating a regular distribution during the stabilization phase as shrub cover approached and reached is maximum potential. In this scenario, mean inter-shrub distances on grazed and protected areas would be expected to initially have a higher variance, followed by a net decrease from 1932 to 1948, then stabilize between 1948 and 2006 and be less variable. 


\section{Methods}

Study site

The study was conducted on the 21 514-ha Santa Rita Experimental Range (SRER) $80 \mathrm{~km}$ south of Tucson, Arizona along the western edge of the semi-desert grassland region of the Sonoran Desert (Brown 1994; $\left.31.81346^{\circ} \mathrm{N}, 110.8875^{\circ} \mathrm{W}\right)$. Annual precipitation in the region is bimodal with a pronounced peak in late summer (July-September monsoon) and a lesser peak in winter. Mean annual precipitation (1922-2007) at the Rodent Station rain gauge situated $0.3 \mathrm{~km}$ from our plots was $354 \mathrm{~mm}$ with an average summer (JuneSeptember) precipitation of $207 \mathrm{~mm}(\mathrm{SD}=73)$ and an average winter precipitation (October-May) of $147 \mathrm{~mm}$ $(\mathrm{SD}=69)$. Vegetation on the SRER ranges from Larrea tridentata desert scrub at the lowest elevations to Quercus spp. woodlands at the highest.

Mesquite (Prosopis spp.) is a leguminous shrub that has extensively invaded grasslands in the Southern Great Plains and southwestern United States. At the SRER, velvet mesquite ( $P$. velutina) is the dominant shrub at 990-1200 m elevation and increases in its cover and density since 1900 have been well documented (McClaran 2003). Our study focused on a 0.8-ha portion $(200 \times 40 \mathrm{~m})$ of a plot established on the SRER by William McGinnies in 1932 to evaluate herbivore effects on vegetation on a sandy loam upland ecological site (National Resource Conservation Service reference no. R041XC319AZ; Breckenfeld and Robinett 2003) at 1100 $\mathrm{m}$ elevation. Soils are classified as Aridisols (fine, mixed, superactive, thermic Ustic Paleargids; sandy clay loam surface texture) in late Pleistocene-age Sasabe-Baboquivari complex with an average maximum clay content of $25 \%$ at $23 \mathrm{~cm}$ depth (Browning et al. 2008). No fires have been recorded on this site since the SRER was established in 1902.

The SRER, representative of many of the grasslands of the Southwestern United States, was severely degraded by the turn of the 20th century, the result of decades of heavy, year-round, unregulated cattle grazing. Cattle were removed shortly after the SRER was established in 1902 to promote vegetation recovery and then reintroduced in 1916. Year-round grazing was practiced from 1916-1972, with stocking rates steadily decreasing from a maximum of 0.17 animal unit years per hectare in 1918 (Browning et al. 2008). A rotational grazing system was implemented in 1972 and maintained through the time of our study (see Mashiri et al. 2008).

\section{Field data collection}

The 74-year record of mesquite stand structure resulted from three exhaustive field census campaigns conducted on plots established on the SRER by William McGinnies in 1932. These plots were initially designed to differentially exclude various combinations of livestock and lagomorphs, but only the livestock exclusion treatments have been maintained since 1952. The 1932 and 1948 mapping efforts were conducted using a survey instrument consisting of a telescopic alidade and plane table (Glendening 1952). Plant locations on these maps were digitized into a geographic information system along with plants mapped in 2006 using a global positioning system (GPS) to achieve $<0.5 \mathrm{~m}$ horizontal accuracy. The geo-coding process for 1932 and 1948 maps yielded positional accuracy similar to that derived from the 2006 GPS campaign (additional details can be found in Browning and Archer 2011). The 2006 field effort encompassed a $100 \times 40 \mathrm{~m}$ area accessible to lagomorphs and livestock since 1916 (hereafter, grazed area) and an adjacent area of equal size protected from livestock since 1932 (hereafter, protected area).

\section{Analyses of spatial pattern on grazed and protected areas}

Point pattern methods based on locations of individuals and area methods based on continuous distributions were used to quantify spatial structure. These combined approaches characterize patterns at multiple spatial scales (Fortin and Dale 2005) and can reveal patterns not discernible from one or the other (e.g., Barot et al. 1999). Hypothesized changes in mesquite spatial patterns were evaluated against a null model of complete spatial randomness (CSR) that describes a pattern generated by a spatial Poisson process with a constant first-order intensity $(\lambda)$ over the study region (Fortin et al. 2002). We implemented CSR as the null hypothesis assuming process stationarity, wherein the effects of the presence or absence of livestock on the establishment and arrangement of mesquite plants does not change over time. In other words, neither the removal of livestock nor the stage of shrub encroachment would alter patterns of mesquite distributions. If mesquite density is spatially non-stationary, the ability to distinguish whether spatial patterns (i.e., clustering) are due to first- or second-order interactions is confounded (Wiegand and Moloney 2004). While null models accounting for heterogeneity exist, parameterizing appropriate alternatives to CSR (i.e., choosing cluster size for a Poisson cluster process or $\lambda$ for a heterogeneous Poisson process) is problematic due to a lack of independent data. Local spatial statistics are unaffected by non-stationarity and were also examined.

The point and area statistics used in this study can detect clustering or positive spatial autocorrelation (values significantly greater than expected under CSR), regular (uniform) patterns, or negative spatial autocorrelation (values significantly less than expected under CSR). Point pattern distributions were based on nearest neighbor distances and all inter-point (plant-plant) distances. Local and global area-based analyses were used to quantify livestock removal effects on spatial autocorrelation and patchiness in mesquite density. Analysis of mesquite spatial patterns in 1932, the year when fences were constructed and livestock were removed from the protected area, were performed using all plants regardless of whether they occurred inside or 
outside of the exclosure. Subsequent analyses for 1932 , 1948, and 2006 were conducted for protected and grazed plots separately to permit comparisons across time.

Second-order point pattern analysis and spatial autocorrelation methods (e.g., statistics of spatial variance) were used to determine if mesquite plants on the protected area exhibited a higher degree of clustering and patchiness than those on the grazed area; and at what distances differences in the degree of clustering occurred. The point pattern analyses quantified the proportion of possible pairs of points (individual plants) in Euclidean space whose members were within a certain distance from one another. We implemented the commonly-reported linearized version of Ripley's $K$ $L(r)$ (Ripley 1976) and the pair correlation function $g(r)$ (Stoyan and Stoyan 1994) using the spatstat package in R version 1.22-1 (Baddeley and Turner 2005). Ripley's isotropic edge correction for rectangular study areas was applied in both cases. This procedure rotates the point pattern to estimate the point intensity outside the study area (Ripley 1991). $L(r)$ and $g(r)$ were calculated using $1.0 \mathrm{~m}$ lags up to $20.0 \mathrm{~m}$ (one half distance of shortest plot dimension).

Ripley's $K$ focuses on a point and counts the number of other points around it within a specified radius; counts are cumulative in that sequential distances encompass all points included in the shorter lags. The Ripley's $K$ calculations were made for each point in the study area to obtain a global statistic. The number of points within the specified radius was then compared to the number of points expected based on a stationary CSR Poisson process. In this study, Ripley's $K$ is reported as $L(r)-r$ for easier interpretation where zero is the theoretical value or expected number of points at a specified radius. A $L(r)-r>0$ means there are more points than would be expected. A $L(r)-r<0$ means there are fewer than expected.

To examine point patterns at a given distance, we calculated the pair correlation function, $g(r)$ (Stoyan and Stoyan 1994), which depicts patterns based on nested rings rather than the circles used to calculate the cumulative $L(r)-r$ metric. The $g(r)$ looks at a neighborhood of points surrounding the specified radius and gives greater weight to points near the radius and less weight to points further away. In this type of weighting, known as an Epanečnikov kernel, points lying outside the bandwidth are not considered in the calculation at that radius. We used a bandwidth of 0.5 $\mathrm{m}$, which approximates one-half of the distance between 1-m steps, to insure rings collectively covered the sample space. Using the "envelope" command in spatstat, we simulated 999 realizations of a pattern of CSR resulting from a homogeneous Poisson process. The simulated points had the same intensity (i.e., point density) as the observed points. The $g(r)$ and $L(r)-r$ metrics were calculated at each step for all 999 simulations. High and low values of the envelopes were the maximum and minimum statistic values at a given lag. We present the
$L(r)-r$ metric to enable direct comparisons with values reported in other studies and the $g(r)$ metric to permit interpretations at discrete distances.

Global Moran's I (Moran 1950) and a local indicator of spatial autocorrelation (LISA; Anselin 1995) were used to quantify spatial autocorrelation of mesquite across grazing treatments and time. We used $5 \times 5 \mathrm{~m}$ cells to characterize spatial heterogeneity in mesquite density (number of shrubs per cell) because smaller sizes would approximate the information conveyed in point pattern analysis, and because this cell size approximated the mean size of mesquite canopies when shrubs were mapped in 1932. Global and local indicators of spatial autocorrelation were calculated using GeoDa software version 0.9.5-i (Anselin et al. 2006) for grazed and protected areas. Moran's I ranges from -1.0 signifying dissimilarity between adjacent values to 1.0 signifying similarity between adjacent values; the expected value for a random (null) pattern is zero. We quantified nearest neighbor correlations (single lag) between each 5 $\times 5 \mathrm{~m}$ cell and its eight neighbors. Significant deviations from random patterns of association relative to the mean density were determined using 999 random permutations of Moran's $I$ for grazing and year comparisons at $\alpha=0.05$.

Local spatial statistics estimate the pattern for each sample location and are useful when the assumption of stationarity (a spatially homogeneous pattern-generating process) may be violated (Getis and Ord 1992). We decomposed the global index of spatial association (Moran's I) into contributions from local neighborhoods using a LISA (Anselin 1995). A target $(t)$ cell with a high mesquite density surrounded by neighboring $(n)$ cells of similarly high mesquite density $\left(\operatorname{high}_{(t)}-\operatorname{high}_{(n)}\right)$ could result from short-range seed dispersal (e.g., majority of seeds falling near parent plant), facilitation, or favorable microsite conditions. Conversely, negative spatial associations $\left(\operatorname{high}_{(t)}-\operatorname{low}_{(n)}\right.$ and $\operatorname{low}_{(t)}-\operatorname{high}_{(n)}$ ) could reflect competition for light or soil moisture or allelopathy (Fortin and Gurevitch 2001).

\section{Spatial patterns and stage of shrub encroachment}

The hypothesis that the mean and variance of intershrub distances would decrease with shrub stand development was evaluated using two distance metrics: the average distance between individual mesquite plants and their nearest neighbor (NN) and the average distance between random locations and the nearest mesquite plant (empty space [ES] function; Baddeley 2010). The ES function is a metric for estimating the degree of infilling, whereas the $\mathrm{NN}$ metric is more sensitive to clustering of plants based on the single nearest neighbor (Baddeley 2010). NN statistics were calculated in ArcGIS version 10.0 using the Near function (Environmental Science Research Institute 2004).We tested for differences in mean NN distances using analysis of variance (ANOVA) between years by grazing treatment and between treatments by year. 
Residuals for mean NN distances mildly violated the normality assumption; analysis of natural log-transformed data did not affect the conclusions. Multiple comparisons were conducted using Tukey's studentized range tests.

The ES function was calculated using a $200 \times 40 \mathrm{~m}$ raster layer with $1.0-\mathrm{m}$ pixels. The $1.0-\mathrm{m}$ pixel size coincided with the sampling interval (or lag distance) for point pattern metrics. The mean distance to the nearest mesquite plant for 4000 pixels in the grazed and protected areas was calculated for each date using the Euclidean Distance tool in ArcGIS. The scale-dependent nature of the ES function prohibited use of ANOVA.

\section{RESULTS}

\section{Spatial pattern on grazed and protected areas}

Mesquite plants in 1932 were not clustered on either the grazed area or the area slated for livestock removal (Fig. 1A). The null hypothesis of CSR could not be rejected for either spatial metric at any lag distance on either the grazed or protected areas when the study was initiated (Fig. 1A, B). Mesquite plants on the protected area in 1948 were clustered at short (1 and $2 \mathrm{~m})$ and intermediate $(8 \mathrm{~m})$ distances (Fig. 1C). Conversely, mesquite plants on the grazed area in 1948 were randomly distributed at all distances. Clustering of mesquite on the protected area in 2006 was even more pronounced and evident at all distances between 1 and $12 \mathrm{~m}$ (Fig. 1D), with peak clustering occurred at 1-2 m. In contrast, there was no evidence of significant clustering on the grazed area at any distance.

At the time plots were established in 1932, mesquite densities were not spatially autocorrelated relative to what would be expected under CSR for the area designated for continued grazing (Moran's $I=0.047$, $P=0.104$ ). In contrast, mesquite densities were weakly, but positively autocorrelated on the area designated for livestock removal (Moran's $I=0.082, P=0.026$; Fig. 2A). The lack of spatial autocorrelation in mesquite density on the grazed area was consistent across time, whereas patterns in mesquite density on the protected area become increasingly positively autocorrelated (2006 Moran's $I=0.261, P=0.001$; Fig. 2A-C). The slope of the line (i.e., Moran's $I$ value) remained flat for the grazed area, but progressively increased on the protected area owing to the development of high-density focal cells surrounded by high-density neighboring cells.

Spatial patterns of local differences in neighbor associations between grazed and protected areas are further illustrated in Fig. 3. Positive associations (lowdensity focal cells surrounded by low-density neighboring cells [designated "low-low"] and high-density focal cells surrounded by high-density neighboring cells [designated "high-high"]) were present on the area slated for livestock and lagomorph exclusion, but were not evident on the area designated for continued livestock grazing. By 1948, additional areas of locally high (dark red) and low (dark blue) shrub densities (relative to random) had developed on both the grazed and protected area, but were much more common and pronounced in the protected area. The areas of relatively high and low shrub density on the protected area persisted to 2006, and in most cases, expanded in size to magnify the spatial contrasts in shrub distributions on grazed and protected areas. To illustrate linkages between global and local measures of association, two $5 \times 5 \mathrm{~m}$ subplots that deviated from mean density most strongly on the protected plot are circled in Fig. 2 and denoted by stars in Fig. 3.

\section{Spatial patterns and stage of shrub encroachment}

The shift toward regularity in mesquite plant distributions hypothesized to occur with stand development was not observed. In fact, the non-cumulative point pattern metric $g(r)$ demonstrated an increasingly clustered distribution on the protected area from 1932 to 2006 (Fig. 1). Mean mesquite NN distances were consistently lower on the protected area relative to the grazed area in all years (Table $1 ; 1932 P=0.014,1948 P$ $=0.003$, and $2006 P=0.001)$. Mean NN distances decreased significantly from 1932 to 1948 on both areas. $\mathrm{NN}$ distances then stabilized on the grazed area between 1948 and 2006, but continued to decrease on the protected area. Variance associated with NN distances, as indicated by coefficients of variation (CV), remained virtually constant from 1932 to 1948 on both grazed and protected areas then declined slightly on both areas from 1948 to 2006.

The mean ES metric (mean distance from a given point to the nearest mesquite plant) also declined on the two areas over time, more so on the protected area than on the grazed area, and in 1948 and 2006 their rank order was reversed (Table 1; Fig. 4). Empty space distances continued to decline on both areas from 1948 to 2006 , but more so for the protected area.

\section{Discussion}

There is active debate regarding the factors contributing to the destabilization of the balance between woody and herbaceous life-forms that has occurred in recent decades to favor trees and shrubs over grasses in many semi-arid and arid regions (Scholes and Archer 1997, Archer 2010). The majority of studies have focused on tree-grass or shrub-grass interactions and the extent to which these contrasting life-forms may partition soil, water, or nutrient resources in time (e.g., phenology) or space (e.g., contrasting root systems) and how climate and disturbance might alter these interactions. Few have looked at spatial patterns. What is lacking is an understanding of how interactions between woody plants might influence patterns of increasing density when interactions with herbaceous vegetation are disrupted and the extent to which density-dependent interactions might limit their maximum potential cover or biomass. Spatial pattern 
A) 1932 (all individuals)
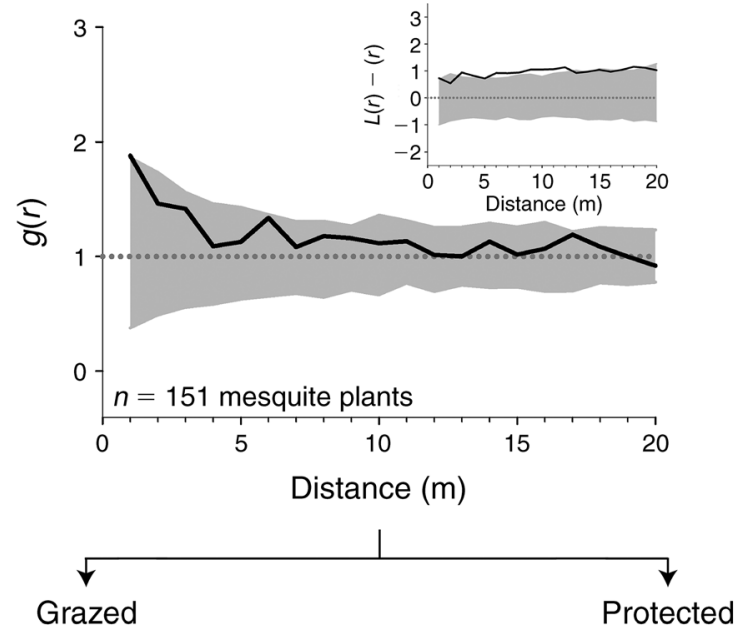

B) 1932
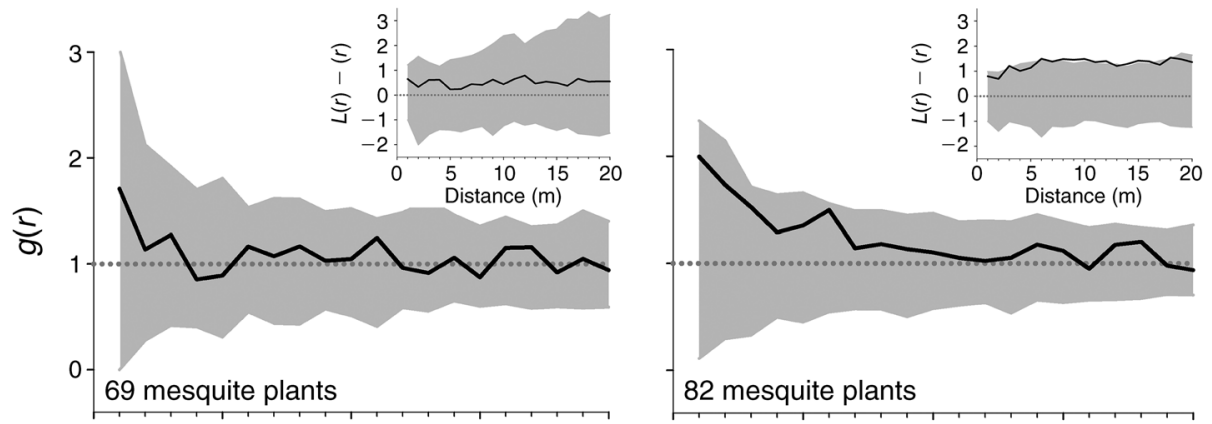

C) 1948
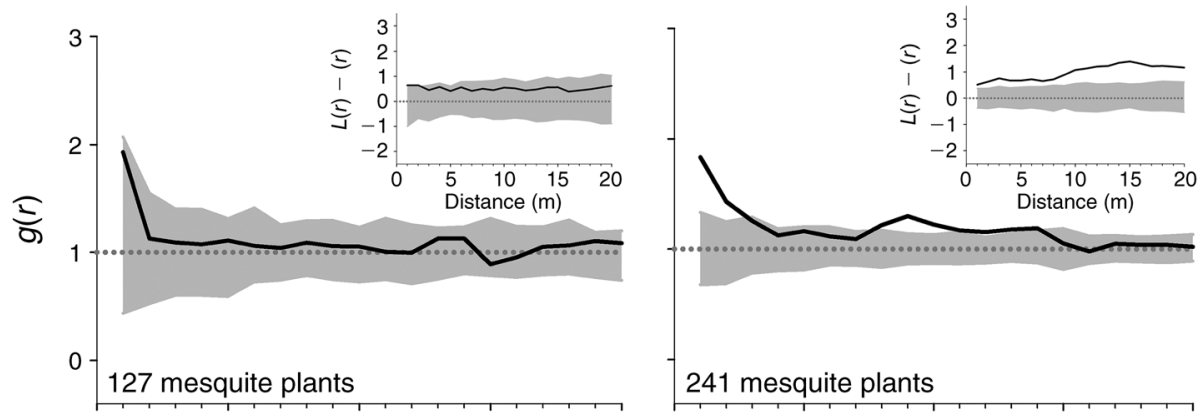

D) 2006
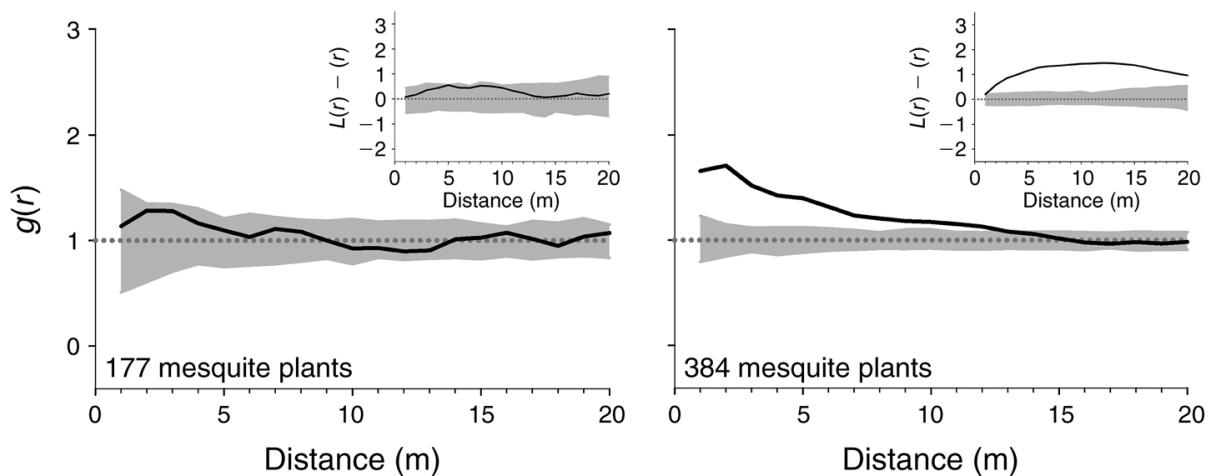

FIG. 1. Univariate point pattern metrics (insets, linearized version of Ripley's $K[L(r)-r]$ and pair correlation function $[g(r)]$ ) derived from mesquite locations mapped in 1932, 1948, and 2006. Metrics (black lines) were calculated at $1.0 \mathrm{~m}$ intervals up to 20 $\mathrm{m}$. The simulation envelope (gray shading) depicts the upper and lower limits from 999 Monte Carlo simulations. A black line outside the gray shaded envelope indicates clustering (line above) or over-dispersion (line below) than expected due to chance at a given distance. Within the simulation envelope, the metric does not differ from that expected at random. 
analyses and experimental removal studies have explored woody plant spacing to assess competition between woody plants and the results are equivocal (reviewed by Sea and Hanan [2011]). With this study we sought to infer the intensity of intraspecific shrubshrub interactions from quantitative analyses of spatial associations over decadal timescales and how these might be mediated by the removal of livestock.

Spatially explicit historical census records are uncommon and tend to be collected at a relatively small spatial extent (Miriti et al. 1998, Bowers et al. 2004). To gauge whether our results represent larger surrounding landscapes, we were limited to estimates of shrub cover. We quantified changes in shrub cover using time series aerial photography $(1936,1971,1996,2005)$ of three additional livestock exclosures on the SRER and the grazed areas surrounding them. Shrub cover on these adjacent sites generally, with comparable soils, tracked those reported for plots in Browning and Archer (2011) and expanded herein, with cover values on the protected areas being consistently higher than those on the grazed areas (data not shown). Additionally, 1932 and 1948 field estimates of plant size and density within the 0.4 ha grazed and protected areas in this study were within the range of values reported by Glendening (1952) for two 1.8 ha plots (see Fig. 2; Browning and Archer 2011). Thus, there is reason to believe that shrub dynamics reported herein are indicative of changes occurring over a broader area.

\section{Contrasting spatial patterns on grazed and protected areas}

Mesquite plants on the protected site were somewhat more aggregated than those on the grazed site when livestock were excluded in 1932. These subtle initial differences in spatial autocorrelation may reflect chance or local variation in subsurface soil properties known to occur on these landscapes (Breckenfeld and Robinett 2003). Although soils on both areas were classified similarly, soils are mapped as "complexes" and inclusions have been estimated to constitute 10$15 \%$ of each soil complex (Breckenfeld and Robinett 1997). Third-order soil surveys are generally based on minimal distributed sampling. A detailed, spatially explicit sampling of sub-surface soil properties within the two areas would clarify these competing interpretations.

We hypothesized that the presence of livestock would promote random patterns of mesquite distribution, whereas their removal would promote clustering. The evidence supported this hypothesis. Mesquite density increased on both the grazed and protected site, but spatial autocorrelation and the development of highdensity patches intensified with time on the protected area through the development of clusters at short distances and subsequent infilling, but did not deviate from random on the grazed area (Figs. 1-3). If independent data had been available to parameterize

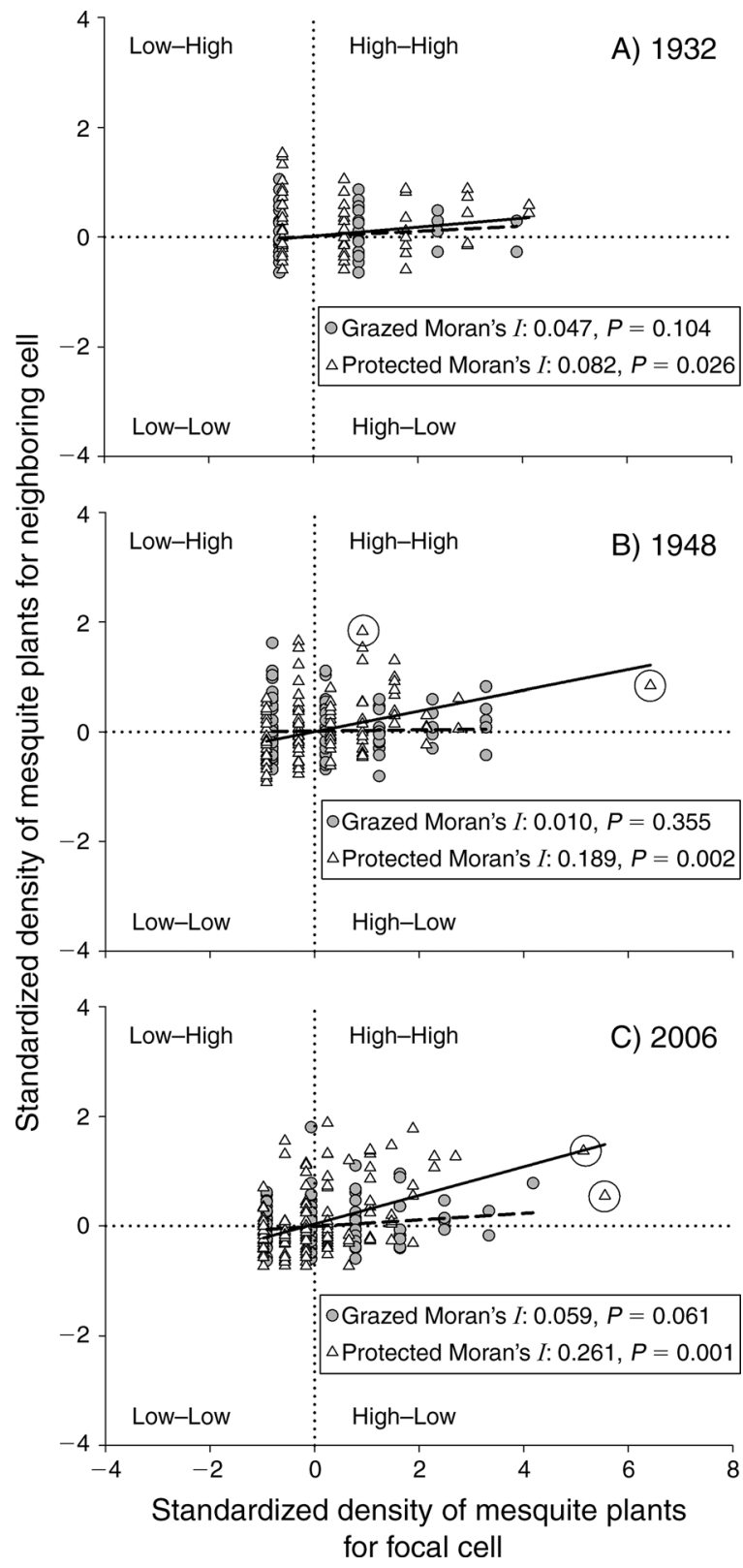

FIG. 2. Global Moran's $I$ (inset values) and scatter plot of the standardized density of mesquite plants within $5 \times 5 \mathrm{~m}$ focal cells in relation to that of its eight neighboring cells on grazed (filled circles, dashed regression lines) and protected (open triangles, solid lines) plots in (A) 1932, (B) 1948, and (C) 2006. Moran's $I$ ranges from -1.0 , signifying dissimilarity between adjacent values, to 1.0 , signifying similarity between adjacent values; the expected value for a random (null) pattern is zero. Density designations represent focal cells-surrounding cells (e.g., "high-high" denotes a high-density focal cell surrounded by high-density neighboring cells). Data for 1932 represent conditions present when livestock exclosures were constructed. $P$ values are based upon 999 randomizations. To illustrate linkages between global and local measures of association, two cells that deviated from mean density most strongly are identified in panels (B) and (C) with circles and in Fig. 3 with stars. 


\section{Local associations (focal-neighbors) for mesquite plant density}

High-High $\square$ High-Low $\square$ Low-High $\square$ Low-Low
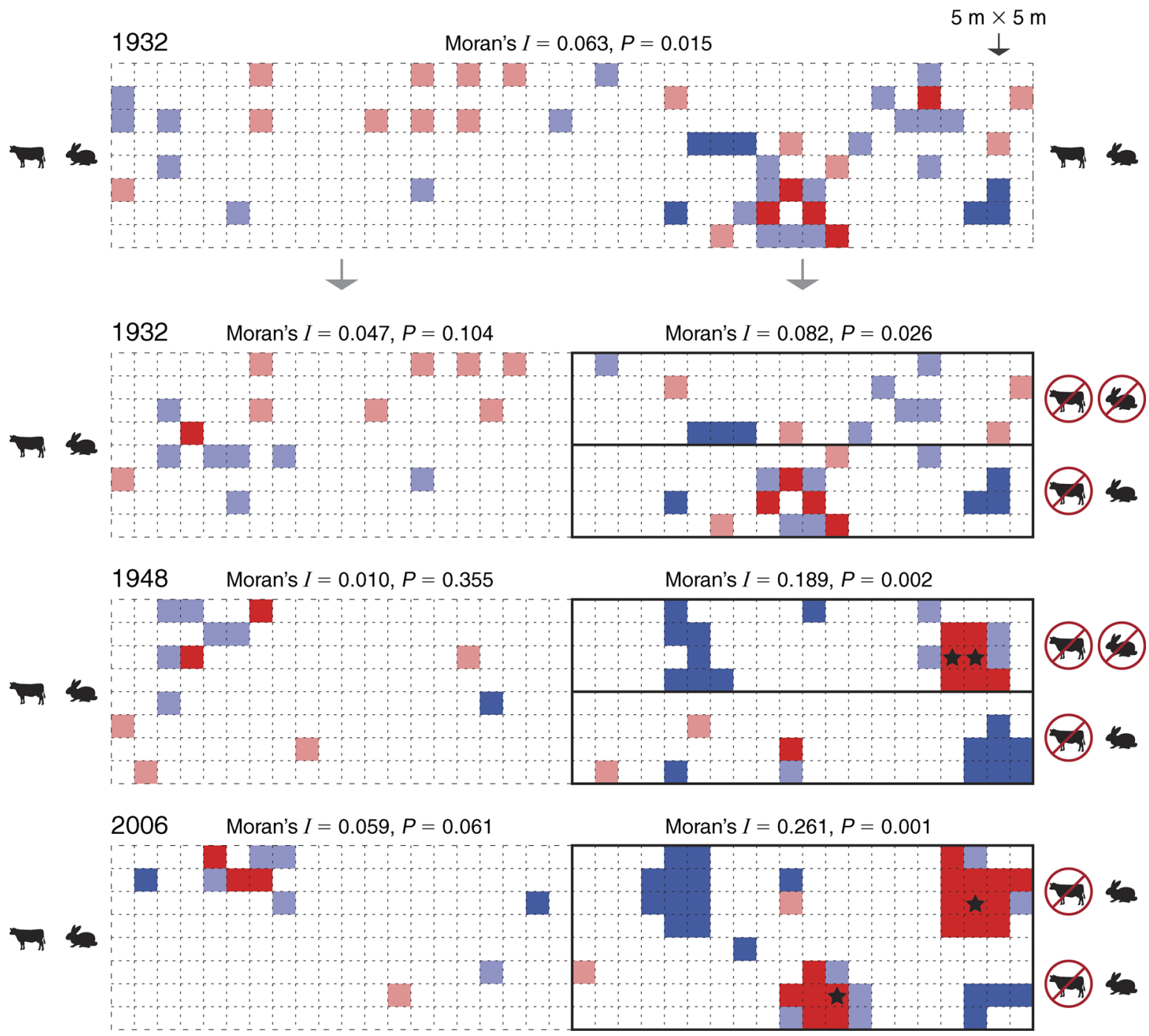

FIG. 3. Local indicator of spatial association (LISA) cluster maps and associated global Moran's $I$ values for mesquite plant density within $3205 \times 5 \mathrm{~m}$ cells (dotted lines). Mesquite density designations (high and low as per Fig. 2) represent focal cellssurrounding cells. White cells indicate associations are not significantly different from random. $P$ values are based upon 999 Monte Carlo simulations. The top panel uses all data to depict density patterns in 1932 when exclosures were constructed. The remaining panels use treatment-specific density data. Cells with strongest deviations from mean density are denoted with black stars (see also circled points in Fig. 2). Animal profiles indicate livestock and lagomorph presence. Symbols in a red circle with a line through it indicate livestock and lagomorph exclusion.

a heterogeneous null model, we may have been less likely to detect significant clustering on the protected site. However, the pattern differences between the grazed and protected areas, and their maintenance and intensification over time, were supported by multiple lines of evidence (global and local, point and area statistics).

The promotion of random mesquite distributions by livestock ostensibly reflects a combination of factors. Cattle are well known for their ability to disperse large numbers of viable seeds away from parent plants and thus provide numerous opportunities for recruitment across a landscape (Brown and Archer 1987). In addition, widespread grazing by livestock may uniformly reduce herbaceous interference, thereby providing more sites suitable for shrub seedling establishment (e.g., Seifan and Kadmon 2006). Conversely, the clustering of mesquite plants observed on the area protected from livestock presumably reflects fewer opportunities for recruitment away from parent plants owing to dual constraints imposed by limited seed dispersal and an herbaceous matrix comprising more 
TABLE 1. Mesquite plant population metrics, spatial statistics, and empty space distance for mesquite plant locations within $100 \times$ $40 \mathrm{~m}$ areas grazed by or protected from livestock since 1932 .

\begin{tabular}{|c|c|c|c|c|c|c|c|c|}
\hline \multirow[b]{2}{*}{ Year } & \multicolumn{2}{|c|}{ Density (no. plants/ha) } & \multicolumn{2}{|c|}{ Canopy area $\left(\mathrm{m}^{2}\right)$} & \multicolumn{2}{|c|}{ Nearest neighbor $(\mathrm{m})$} & \multicolumn{2}{|c|}{ Empty space (m) } \\
\hline & Grazed & Protected & Grazed & Protected & Grazed & Protected & Grazed & Protectec \\
\hline 1932 & 172.5 & 202.5 & $4.0^{\mathrm{A}, \mathrm{a}}(0.70)$ & $3.0^{\mathrm{B}, \mathrm{a}}(0.70)$ & $4.0(0.55)$ & $4.6(0.72)$ & $7.0^{\mathrm{A}}(1.3)$ & $4.7^{\mathrm{A}}(3.0$ \\
\hline 1948 & 317.5 & 602.5 & $2.6^{\mathrm{A}, \mathrm{b}}(0.69)$ & $2.0^{\mathrm{B}, \mathrm{b}}(0.70)$ & $3.1(0.57)$ & $2.3(0.66)$ & $6.0^{\mathrm{A}}(1.0)$ & $3.6^{\mathrm{B}}(0.7$ \\
\hline 2006 & 442.5 & 960.0 & $2.4^{\mathrm{A}, \mathrm{b}}(0.54)$ & $1.6^{\mathrm{B}, \mathrm{c}}(0.63)$ & $2.6(0.59)$ & $1.8(0.61)$ & $3.8^{\mathrm{A}}(0.6)$ & $2.5^{\mathrm{B}}(0.2$ \\
\hline
\end{tabular}

Notes: Mesquite plant population metrics are density and canopy area. Values for canopy area are means with SE in parentheses. Spatial statistics are distance to nearest neighbor (NN, mesquite-to-mesquite) and its coefficient of variation in parentheses $(\mathrm{CV}=$ $\mathrm{SD} /$ mean), and empty space distance (distance from the center of a given $1.0 \times 1.0 \mathrm{~m}$ cell to nearest mesquite plant and its $\mathrm{CV}$ in parentheses). Significant differences $(\alpha=0.05)$ across treatments are denoted with capital letters; differences between years are denoted with lower case letters (means that share a letter are not significantly different). See Fig. 4 for patterns of empty space distribution.

competitive plants and hence a restricted subset of locations for shrub seedling establishment. These contrasting scenarios point to the need for a better understanding of seed dispersal and grass-shrub seedling interactions and the integration of these competing perspectives into a framework for predicting the effects of alternative livestock management practices on the shrub encroachment process.

1932

Grazed Protected

Maximum distance $=22.6 \mathrm{~m}$

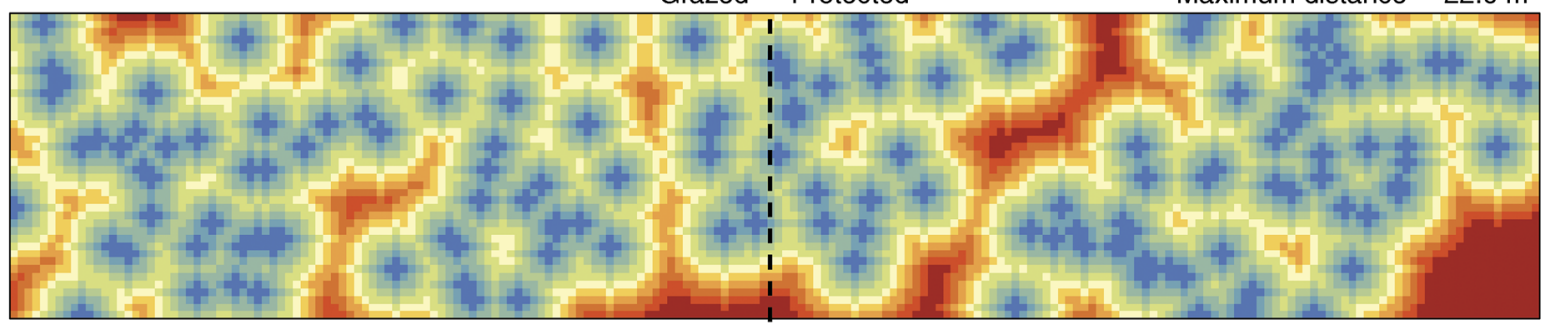

1948

Maximum distance $=12.8 \mathrm{~m}$

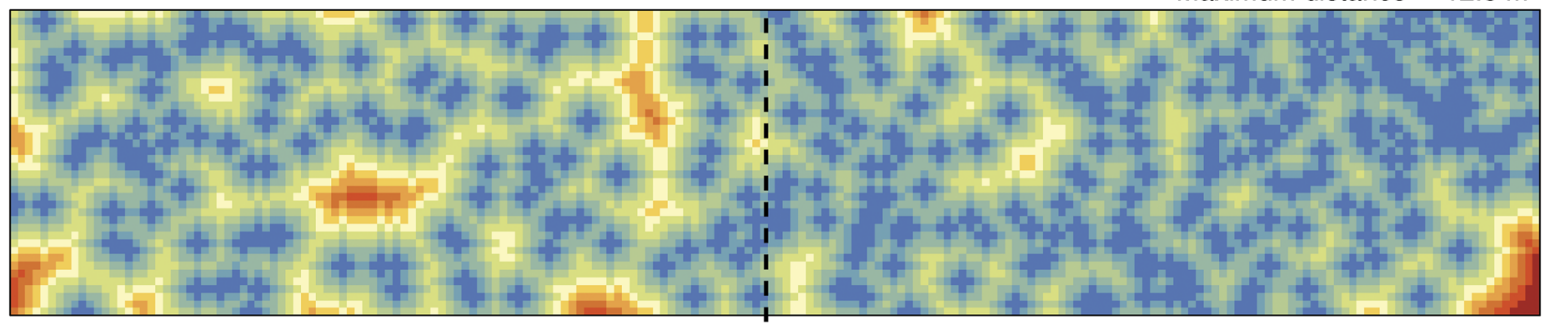

2006

Maximum distance $=10.0 \mathrm{~m}$

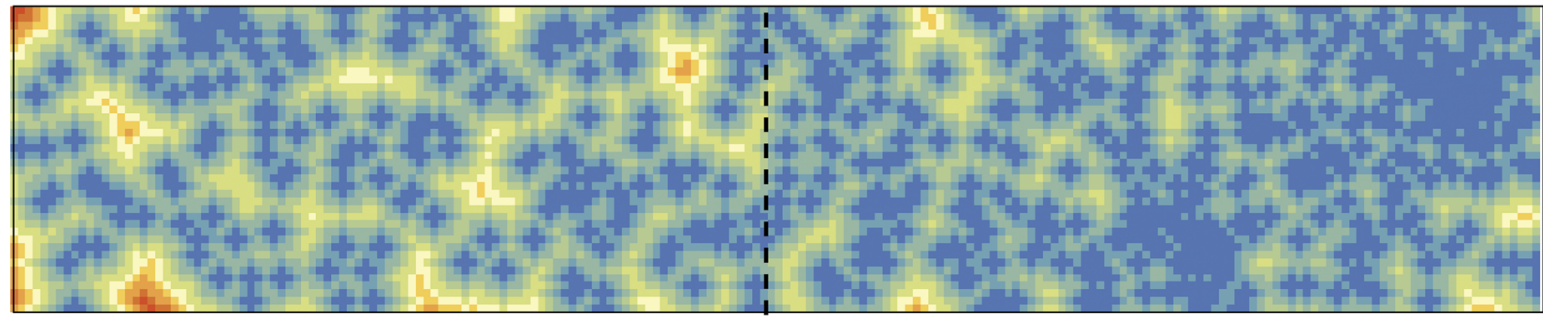

$200 \mathrm{~m}$

Distance to nearest mesquite plant $(\mathrm{m})$

\begin{tabular}{|c|c|c|c|}
\hline $0-1.00$ & $3.01-4.00$ & $6.01-7.00$ & $9.01-10.00$ \\
\hline $1.01-2.00$ & $4.01-5.00$ & $7.01-8.00$ & $10.01-22.60$ \\
\hline $2.01-3.00$ & $5.01-6.00$ & $8.01-9.00$ & \\
\hline
\end{tabular}

FIG. 4. Maps depicting the distance in meters from a given 1.0-m pixel (8000 total pixels) to the nearest mesquite plant in 1932 , 1948, and 2006. Maximum distances (upper right of each panel) are for the entire area; see Table 1 for mean distances on grazed vs. protected areas. Livestock were excluded from the right half of the area starting in 1932. Prior to that time, the entire area had been heavily and continuously grazed. 


\section{Spatial patterns and stage of shrub encroachment}

Nearest neighbor and second-order spatial statistics have been used to demonstrate regular patterns among woody plants and infer intraspecific competition (e.g., Smith and Goodman 1986, Getzin et al. 2006, Meyer et al. 2008). We hypothesized that the distribution of mesquite would become increasingly regular as mesquite stands transitioned from the encroachment phase to the stabilization phase. Mesquite density increased substantially on both the grazed and protected site throughout the 74-yr period (Table 1) and mesquite associations in the protected area exhibited a higher degree of patchiness with spatial associations both higher and lower than expected, yielding pockets of high and low mesquite density (Fig. 3). Thus, there should have been ample opportunity for density-dependent interactions to promote a regular spatial distribution, particularly on the protected site where densities were substantially higher. However, we saw no evidence that shrub recruitment was leveling off and no evidence of a progression toward a regular distribution that might indicate self-thinning or intraspecific density-dependent interactions. To the contrary, spatial aggregation on the protected area became more pronounced through 1948 and 2006.

There are several lines of evidence suggesting shrubshrub interactions should intensify as shrub abundance increases. Field studies in desert systems have long noted both clumped and regular patterns of shrub distribution and the occurrence of overlapping root systems, and from this have inferred that distributions shift from clumped to regular as shrubs grow and stands develop (e.g., Phillips and MacMahon 1987, Wiegand et al. 2005). These inferences have been supported, at least partially, by neighbor removal experiments (Fonteyn and Mahall 1981, Manning and Barbour 1988, Ansley et al. 1998) and time-series aerial photos showing declines in rates of shrub cover increase with increasing shrub cover (Fensham et al. 2005) and shifts from clustered to regular distributions (Goslee et al. 2003). Furthermore, mesquite plants on our site have extensive shallow lateral root systems that extend well beyond their canopies (Cable 1980). These shallow roots are important to plant water balance (Ansley et al. 1991) and ostensibly influence intraspecific competition for soil resources. Indeed, field data from the Santa Rita site have documented decreases in shrub growth rates (Glendening 1952) and declines in the probability of shrub recruitment (Browning and Archer 2011) with increasing shrub abundance. Furthermore, continentalscale assessments suggest that mean annual precipitation (MAP) sets the upper limit for potential shrub cover (Sankaran et al. 2005). Shrub cover on landscapes with soils similar to those on the long-term plots in our study have approximated the predicted upper limit (approximately $37 \%$ for $370 \mathrm{~mm}$ MAP; Browning et al. 2008), suggesting there has been ample time for shrub-shrub interactions to influence patterns of association. Thus, there are numerous reasons to expect the intensity of shrub-shrub interactions to increase with time on this site. Why then have we not seen evidence of self-thinning on our long term plots?

Field-estimated shrub cover on our long-term plots in 2006 (15-22\% on grazed and protected areas, respectively; Browning and Archer 2011) was well below the predicted maximum for our annual rainfall (37\%, Sankaran et al. 2005). These low cover values likely reflect a pasture-wide herbicide application in 1964 and 1965 conducted as part of range management study. This would not necessarily have influenced patterns of association, as shrubs vegetatively regenerated quickly after the herbicide application (see Browning and Archer [2011] for details). Even so, it reduced shrub cover and may have relaxed the intensity of plant interactions. It could also be that intraspecific competition in this system is minimal. This possibility is consistent with the tendency toward more pronounced spatial aggregation with time on the protected area (Figs. 1, 3, 4) and with results from field experiments showing little or no shrub response to neighbor removals in other systems (Miller and Huenneke 2000, Simmons 2003).

If intraspecific competition is not important, what then what might explain the limits to woody cover imposed by mean annual precipitation predicted by Sankaran et al. (2005) and locally documented by Browning et al. (2008) for our study site? One hypothesis is related to potential hydraulic constraints on shrub size in dryland systems (e.g., Sperry and Hacke 2002, Hacke et al. 2006). As shrubs approach their upper size limit for a site with a given soil texture, depth, topographic setting, etc., their ability to maintain continuity in xylem water transport may become increasingly jeopardized and lead to higher probabilities of branch or wholecanopy mortality. This loss of plant branch systems or canopies would constitute reductions in canopy cover that would have to be compensated for by recruitment of new plants or growth of other, smaller plants if standlevel canopy cover were to be maintained. Support for this proposition comes from observations of height asymptotes and shifts in leaf-stem biomass allocation for mesquite in a variety of Chihuahuan Desert landforms (Martinez and Lopez-Portillo 2003); and the utility of allometry theory in characterizing sizeabundance relationships within creosote bush stands (Larrea spp.; Allen et al. 2008).

Mechanisms imposing the upper limits of woody plant stature and density on this site thus remain open to speculation. However, their elucidation has important implications for predicting the effects of tree and shrub proliferation in drylands, a globally extensive phenomenon, on land-surface-atmosphere interactions, primary production, and carbon cycling.

\section{ACKNOWLEDGMENTS}

We acknowledge the extraordinary legacy of W. McGinnies and G. Glendening. Historic maps were provided by the SRER Archive Database at the University of Arizona. Funding was 
provided through the U.S. EPA STAR Graduate Fellowship FP-91637801-3 to D. M. Browning, NSF grant DEB-0824708 to J. Franklin, and NASA grant NAG5-11238 and NSF grant DEB-9981723 to S. R. Archer. U.S. EPA has not officially endorsed this publication and the views expressed herein may not reflect the views of the U.S. EPA, NSF, or NASA. We thank K. Predick, M. McClaran, K. Havstad, J. Brown, J. Karl, and S. J. Rey for helpful comments and insightful discussions. We thank two anonymous reviewers who provided thoughtful feedback that improved the clarity of the manuscript.

\section{Literature Cited}

Adler, P. B., D. A. Raff, and W. K. Lauenroth. 2001. The effect of grazing on the spatial heterogeneity of vegetation. Oecologia 128:465-479.

Allen, A. P., W. T. Pockman, C. Restrepo, and B. T. Milne. 2008. Allometry, growth and population regulation of the desert shrub Larrea tridentata. Functional Ecology 22:197204.

Allington, G. R. H., and T. J. Valone. 2010. Reversal of desertification: The role of physical and chemical soil properties. Journal of Arid Environments 74:973-977.

Anselin, L. 1995. Local indicators of spatial associationLISA. Geographical Analysis 27:93-115.

Anselin, L., I. Syabri, and Y. Kho. 2006. GeoDa: An introduction to spatial data analysis. Geographical Analysis 38:5-22.

Ansley, R. J., P. W. Jacoby, and R. A. Hicks. 1991. Leaf and whole plant transpiration in honey mesquite following severing of lateral roots. Journal of Range Management 44:577-583.

Ansley, R. J., B. A. Trevino, and P. W. Jacoby. 1998. Intraspecific competition in honey mesquite: leaf and whole plant responses. Journal of Range Management 51:345-352.

Archer, S. 1994. Woody plant encroachment into southwestern grasslands and savannas: rates, patterns, and proximate causes. Pages 13-68 in M. Vavra, W. Laycock, and R. Pieper, editors. Ecological implications of livestock herbivory in the West. Society for Range Management, Denver, Colorado, USA.

Archer, S. 2010. Rangeland conservation and shrub encroachment: new perspectives on an old problem. Pages 53-97 in J. du Toit, R. Kock, and J. Deutsch, editors. Wild rangelends: conserving wildlife while maintaining livestock in semi-arid ecosystems. Wiley-Blackwell, Oxford, UK.

Ash, A. J., J. G. McIvor, J. J. Mott, and M. H. Andrew. 1997. Building grass castles: integrating ecology and management of Australia's tropical tallgrass rangelands. Rangeland Journal 19:123-144.

Asner, G. P., A. J. Elmore, L. P. Olander, R. E. Martin, and T. Harris. 2004. Grazing systems, ecosystem responses, and global change. Annual Review of Environmental Resources 29:261-299.

Baddeley, A. 2010. Analysing spatial point patterns in R. Commonwealth Scientific and Industrial Research Organization. Collingwood, Victoria, Australia.

Baddeley, A., and R. Turner. 2005. spatstat: an R package for analyzing spatial point patterns. Journal of Statistical Software 12:1-42.

Barger, N. N., S. Archer, J. Campbell, C. Huang, J. Morton, and A. Knapp. 2011. Woody plant encroachment and the North American carbon budget. Journal of Geophysical Research Biogeosciences 116:G00K07.

Barot, S., J. Gignoux, and J. C. Menaut. 1999. Demography of a savanna palm tree: predictions from comprehensive spatial pattern analyses. Ecology 80:1987-2005.

Bestelmeyer, B. T., D. P. Goolsby, and S. R. Archer. 2011. Spatial perspectives in state-and-transition models: a missing link to land management? Journal of Applied Ecology 48:746-757.

Bowers, J. E., R. M. Turner, and T. L. Burgess. 2004. Temporal and spatial patterns in emergence and early survival of perennial plants in the Sonoran Desert. Plant Ecology 172:107-119.

Breckenfeld, D. J., and D. Robinett. 1997. Soil and range resource inventory of the Santa Rita Experimental Range Pima County, Arizona. Natural Resources Conservation Service, U.S. Department of Agriculture, Tucson, Arizona, USA.

Breckenfeld, D. J., and D. Robinett. 2003. Soil and ecological sites of the Santa Rita Experimental Range. Pages 157-165 in M. P. McClaran, P. F. Ffolliott, and C. B. Edminster, editors. Santa Rita Experimental Range: one hundred years (1903-2003) of accomplishments and contributions. Conference Proceedings, 30 October-1 November 2003, Tucson, Arizona. U.S. Department of Agriculture, Forest Service, Rocky Mountain Research Station, Ogden, Utah, USA.

Brown, D. E. 1994. Semidesert grassland. Pages 123-131 in D. E. Brown, editor. Biotic communities: southwestern United States and northwestern Mexico. University of Utah Press, Salt Lake City, Utah, USA.

Brown, J. R., and S. Archer. 1987. Woody plant seed dispersal and gap formation in a North American sub-tropical savanna woodland: the role of domestic herbivores. Vegetatio 73:73-80.

Browning, D. M., and S. R. Archer. 2011. Protection from livestock fails to deter shrub proliferation in a desert landscape with a history of heavy grazing. Ecological Applications 21:1629-1642.

Browning, D. M., S. R. Archer, G. P. Asner, M. P. McClaran, and C. A. Wessman. 2008. Woody plants in grasslands: postencroachment dynamics. Ecological Applications 18:928944.

Cable, D. R. 1980. Seasonal patterns of soil-water recharge and extraction on semi-desert ranges. Journal of Range Management 33:9-15.

Chamberlin, T. C. 1965. Method of multiple working hypotheses. Science 148:754-769.

Condit, R., et al. 2000. Spatial patterns in the distribution of tropical tree species. Science 288:1414-1418.

de Knegt, H. J., T. A. Groen, C. van de Vijver, H. H. T. Prins, and F. van Langevelde. 2008. Herbivores as architects of savannas: nducing and modifying spatial vegetation patterning. Oikos 117:543-554.

Eldridge, D. J., M. A. Bowker, F. T. Maestre, E. Roger, J. F. Reynolds, and W. G. Whitford. 2011. Impacts of shrub encroachment on ecosystem structure and functioning: towards a global synthesis. Ecology Letters 14:709-722.

Ellison, A. M., et al. 2005. Loss of foundation species: consequences for the structure and dynamics of forested ecosystems. Frontiers in Ecology and the Environment 3:479-486.

Environmental Science Research Institute. 2004. ArcGIS v. 9.0. ESRI, Redlands, California, USA.

Fensham, R. J., R. J. Fairfax, and S. Archer. 2005. Rainfall, land use and woody vegetation cover change in semi-arid Australian savanna. Journal of Ecology 93:596-606.

Fonteyn, P. J., and B. E. Mahall. 1981. An experimental analysis of structure in a desert plant community. Journal of Ecology 69:883-896.

Fortin, M.-J., and M. Dale. 2005. Spatial analysis: a guide for ecologists. Cambridge University Press, Cambridge, UK.

Fortin, M.-J., M. R. T. Dale, and J. Ver Hoef. 2002. Spatial analysis in ecology. Pages 2051-2058 in A. H. El-Shaarawi and W. W. Piegorsch, editors. Encyclopedia of environmetrics. John Wiley and Sons, Chichester, UK.

Fortin, M.-J., and J. Gurevitch. 2001. Mantel tests: Spatial structure in field experiments. Pages $308-326$ in S. M. 
Scheiner and J. Gurevitch, editors. Design and analysis of ecological experiments. Oxford University Press, Oxford, UK.

Franklin, J. 2010. Spatial point patterns analysis of plants. Pages 113-123 in S. J. Rey and L. Anselin, editors. Perspectives on spatial data analysis. Springer, New York, New York, USA.

Fuhlendorf, S. D., S. R. Archer, F. E. Smeins, D. M. Engle, and C. A. Taylor. 2008. The combined influence of grazing, fire and herbaceous productivity on tree-grass interactions. Pages 219-236 in O. W. Van Auken, editor. Western North American Juniperus communities. A dynamic vegetation type. Springer, New York, New York, USA.

Getis, A., and J. K. Ord. 1992. The analysis of spatial association by use of distance statistics. Geographical Analysis 24:189-206.

Getzin, S., C. Dean, F. L. He, J. A. Trofymow, K. Wiegand, and T. Wiegand. 2006. Spatial patterns and competition of tree species in a Douglas-fir chronosequence on Vancouver Island. Ecography 29:671-682.

Glendening, G. E. 1952. Some quantitative data on the increase of mesquite and cactus on a desert grassland range in southern Arizona. Ecology 33:319-328.

Goslee, S., K. M. Havstad, D. P. C. Peters, A. Rango, and W. H. Schlesinger. 2003. High-resolution images reveal rate and pattern of shrub encroachment over six decades in New Mexico, USA. Journal of Arid Environments 54:755-767.

Hacke, U. G., J. S. Sperry, J. K. Wheeler, and L. Castro. 2006. Scaling of angiosperm xylem structure with safety and efficiency. Tree Physiology 26:689-701.

Holechek, J. L., R. D. Pieper, and C. H. Herbel. 2000. Range management: principles and practices. Fourth edition. Prentice-Hall, London, UK.

Huntly, N. 1991. Herbivores and the dynamics of communities and ecosystems. Annual Review of Ecology and Systematics 22:477-503.

Jurena, P. N., and S. Archer. 2003. Woody plant establishment and spatial heterogeneity in grasslands. Ecology 84:907-919.

Kneuper, C. L., C. B. Scott, and W. E. Pinchak. 2003. Consumption and dispersion of mesquite seeds by ruminants. Journal of Range Management 56:255-259.

Ludwig, J. A., B. P. Wilcox, D. D. Breshears, D. J. Tongway, and A. C. Imeson. 2005. Vegetation patches and runofferosion as interacting ecohydrological processes in semiarid landscapes. Ecology 86:288-297.

Manning, S. J., and M. G. Barbour. 1988. Root systems, spatial patterns, and competition for soil-moisture between two desert subshrubs. American Journal of Botany 75:885-893.

Martinez, A. J., and J. Lopez-Portillo. 2003. Allometry of Prosopis glandulosa var. torreyana along a topographic gradient in the Chihuahuan desert. Journal of Vegetation Science 14:111-120.

Mashiri, F. E., M. P. McClaran, and J. S. Fehmi. 2008. Shortand long-term vegetation change related to grazing systems, precipitation, and mesquite cover. Rangeland Ecology and Management 61:368-379.

McClaran, M. P. 2003. A century of vegetation change on the Santa Rita Experimental Range. Pages 16-33 in M. P. McClaran, P. F. Ffolliott, and C. B. Edminster, editors. Santa Rita Experimental Range: one-hundred years (19032003) of accomplishments and contributions. Conference Proceedings, 30 October-1 November 2003, Tucson, Arizona. U.S. Department of Agriculture, Forest Service, Rocky Mountain Research Station, Ogden, Utah, USA.

Meyer, K. M., D. Ward, K. Wiegand, and A. Moustakas. 2008. Multi-proxy evidence for competition between savanna woody species. Perspectives in Plant Ecology Evolution and Systematics 10:63-72.

Miller, R. E., and L. F. Huenneke. 2000. Demographic variation in a desert shrub, Larrea tridentata, in response to a thinning treatment. Journal of Arid Environments 45:315323.

Miriti, M. N. 2007. Twenty years of changes in spatial association and community structure among desert perennials. Ecology 88:1177-1190.

Miriti, M. N., H. E. Howe, and S. J. Wright. 1998. Spatial patterns of mortality in a Colorado desert plant community. Plant Ecology 136:41-51.

Montané, F., P. Casals, and M. R. T. Dale. 2012. How spatial heterogeneity of cover affects patterns of shrub encroachment in mesic grasslands. PLoS ONE 12(6):e28652.

Moran, P. A. P. 1950. Notes on continuous stochastic phenomena. Biometrika 37:17-12.

Naito, A. T., and D. M. Cairns. 2011. Patterns and processes of global shrub expansion. Progress in Physical Geography 35:423-442.

Neff, J. C., A. P. Ballantyne, G. L. Farmer, N. M. Mahowald, J. L. Conroy, C. C. Landry, J. T. Overpeck, T. H. Painter, C. R. Lawrence, and R. L. Reynolds. 2008. Increasing aeolian dust deposition in the western United States linked to human activity. Nature Geoscience 1:189-195.

Okin, G. S., P. D'Odorico, and S. R. Archer. 2009. Impact of feedbacks on Chihuahuan desert grasslands: transience and metastability. Journal of Geophysical Research Biogeosciences 114:G01004.

Perry, G. L. W., B. P. Miller, and N. J. Enright. 2006. A comparison of methods for the statistical analysis of spatial point patterns in plant ecology. Plant Ecology 187:59-82.

Peters, D. P. C., R. A. Pielke, B. T. Bestelmeyer, C. D. Allen, S. Munson-McGee, and K. M. Havstad. 2004. Cross-scale interactions, nonlinearities, and forecasting catastrophic events. Proceedings of the National Academy of Sciences USA 101:15130-15135.

Phillips, D. L., and J. A. MacMahon. 1987. Competition and spacing patterns in desert shrubs. Journal of Ecology 69:97115.

Ravi, S., and P. D’Odorico. 2009. Post-fire resource redistribution and fertility island dynamics in shrub encroached desert grasslands: a modeling approach. Landscape Ecology 24:325-335.

Rayburn, A. P., and T. A. Monaco. 2011. Linking plant spatial patterns and ecological processes in grazed Great Basin plant communities. Rangeland Ecology and Management 64:276282.

Rietkerk, M., P. Ketner, J. Burger, B. Hoorens, and H. Olff. 2000. Multiscale soil and vegetation patchiness along a gradient of herbivore impact in a semi-arid grazing system in West Africa. Plant Ecology 148:207-224.

Ripley, B. D. 1976. The second-order analysis of stationary point processes. Journal of Applied Probability 13:255-266.

Ripley, B. D. 1991. Statistical inference for spatial processes. Cambridge University Press, New York, New York, USA.

Sankaran, M., et al. 2005. Determinants of woody cover in African savannas. Nature 438:846-849.

Scheffer, M., and S. R. Carpenter. 2003. Catastrophic regime shifts in ecosystems: linking theory to observation. Trends in Ecology and Evolution 18:648-656.

Scholes, R. J., and S. R. Archer. 1997. Tree-grass interactions in savannas. Annual Review of Ecology and Systematics 28:517-544.

Sea, W. B., and N. P. Hanan. 2011. Self-thinning and tree competition in savannas. Biotropica 44:189-196.

Seifan, M., and R. Kadmon. 2006. Indirect effects of cattle grazing on shrub spatial pattern in a mediterranean scrub community. Basic and Applied Ecology 7:496-506.

Simmons, M. T. 2003. Tree-grass and tree-tree interactions in a temperate savanna. Texas A\&M University, College Station, Texas, USA.

Smith, T. M., and P. S. Goodman. 1986. The effect of competition on the structure and dynamics of Acacia 
savannas in southern Africa. Journal of Ecology 74:10311044.

Sperry, J. S., and U. G. Hacke. 2002. Desert shrub water relations with respect to soil characteristics and plant functional type. Functional Ecology 16:367-378.

Stoyan, D., and H. Stoyan. 1994. Fractals, random shapes, and point fields: methods of geometrical statistics. John Wiley and Sons, Chichester, UK.

Throop, H. L., and S. R. Archer. 2008. Shrub (Prosopis velutina) encroachment in a semidesert grassland: spatial- temporal changes in soil organic carbon and nitrogen pools. Global Change Biology 14:2420-2431.

Van Auken, O. W. 2000. Shrub invasions of North American semiarid grasslands. Annual Review of Ecology and Systematics 31:197-215.

Wiegand, K., D. Ward, and D. Saltz. 2005. Multi-scale patterns and bush encroachment in an arid savanna with a shallow soil layer. Journal of Vegetation Science 16:311-320.

Wiegand, T., and K. A. Moloney. 2004. Rings, circles, and nullmodels for point pattern analysis in ecology. Oikos 104:209229. 